\title{
Entry and Exit Strategies in English and Arabic
}

Lec. Mohammed Abed Saleh Albadri/ University of Wasit, College of Education for Human Sciences, Department of English Language, and Literature

Asst. Lec. Salah Hadi Shuker/ Ministry of Education, Wasit Education Directorate

\section{Introduction}

From a sociolinguistic perspective, greetings and farewells are part of what Goffman (197r) calls the ethnography of encounter. These encounters are not randomly made. They are governed by a set of strategies which enable participants to enter and exit conversations in a socially accepted manner. Such strategies are tackled within the scope of conversation analysis, henceforth CA, which is an approach that studies talk in interaction. It grew out of the ethnomethodological tradition in sociology, embracing both verbal and non-verbal conduct. This approach is initiated during the late $190 \cdot \mathrm{s}$ of the last century by the works of Harold Garfinkel and Erving Goffman, then, developed in the late 197.s and early 19\% $\cdot \mathrm{s}$ by the sociologists Harvey Sacks, Emanuel Schegloff and Gail Jefferson. Today CA is an established method used in sociology, anthropology, linguistics, speech-communication and psychology.

This study is going to detect entry and exit strategies in English and Arabic by analyzing two episodes of 'The Doctors' show in its American and Arabic versions. The study conveys this topic on two interrelated scales as it employs sociolinguistic and discourse perspectives altogether, discussing how the two approaches cooperate to give a comprehensible view of the nature of entering and exiting conversation. Meanwhile, the data to be analyzed does not convey an ordinary type of conversation but a special kind of conversation, that is called institutional talk. This involves some specialization and respecification of the interactional relevance. It refers to conversations that take place under focused and specialized conditions like media, courts, educational institutions and health establishments (Gumperz, $r \ldots l: r \mid \Lambda)$. For the most of our knowledge, such type of conversation is not expected to show everything about talk in interaction, yet, it shows a big deal of conformity to the premises of conversation analysis, and it appears to have a good amount of flexibility.

\section{r. Conversation and Conversation Analysis}

Conversation may be seen as the most common use of human language. Human beings are regularly engaged in conversational interactions that serve many functions and purposes within society. Heritage $(199 \cdot: \curlyvee \wedge r)$ argues that social interaction is the basic means through which the business of the social world is transacted, the identities of its participants are affirmed or denied, and its cultures are transmitted, renewed and modified (Cited in: Liddicoat, $\left.r_{\cdots} \cdot v^{\prime}\right)$ ). Therefore, conversation is the way in which people socialize and develop their relationships with each other. When people converse they engage in a form of linguistic communication with the aid of paralinguistic features, including eye gaze, body posture, silences and the real world context in which the talk is produced (ibid: $r$ ). 
Conversation analysis (CA) is an approach to the study of talk in interaction which grew out of the ethnomethodological tradition in sociology, embracing both verbal and non-verbal conduct. This approach is initiated during the late $190 . \mathrm{s}$ of the last century by the works of Harold Garfinkel and Erving Goffman, and then developed in the late $197 \cdot \mathrm{s}$ and early $19 \% \cdot \mathrm{s}$ by the sociologists Harvey Sacks, Emanuel Schegloff and Gail Jefferson. Today CA is an established method used in sociology, anthropology, linguistics, speech-communication and psychology. It is particularly influential in interactional sociolinguistics, discourse analysis and discursive psychology.

Ethnomethodology is a field of sociology through which Garfinkel sought to study the social structure of everyday experience and to develop an understanding of "how the structures of everyday activities are ordinarily and routinely produced and maintained" (Garfinkel, 197v: r०). It also gave increased prominence to participants' understandings of social action and viewed the participants themselves as knowledgeable agents who attribute meaning to their social actions in ways which were central to the unfolding of those actions (ibid: ${ }^{\top}$ ).

To sum up the whole idea, CA is "the systematic analysis of the talk produced in everyday situations of human-interaction: talk in interaction" (Hutchby \& Wooffitt $r \cdots \wedge: 11)$. It aims "to reveal the organized reasoning procedures, which inform the production of naturally occurring talk" (ibid). CA attempts to reveal these procedures by studying the very details of how people speak and interact. These seemingly small details can contribute to our understanding of how all the conversation works. To CA researchers, nothing is to be considered trivial until it has been subjected to thorough analysis.

\section{r. $\quad$ Conversation vs. Talk-in-interaction}

Goffman (197 : 70 ) presents a similar view to that of Garfinkel. He argues that the study of speaking is not simply a matter of narrowly focused linguistic descriptions of language, but rather that interaction had its own system of rules and structures which should not, necessarily, be linguistic in nature. This means that the study of language in purely linguistic terms could not adequately account for the nature of language-in-use. Therefore, we see him rejects the organization of talk in terms of who speaks to whom in what language, preferring what is called a social encounter.

Leaving the purely linguistic framework, Goffman (197v) maintained that there are at least four universal sets of communication signals. These are: open/close signals in which the speaker initiates a conversation spontaneously and unconsciously, close or pre-closing signals such as (well, so, uh) which give the interlocutor the opportunity to stop or close his talk, backchannel signals that provide feedback to the dominant interlocutor by indicating that the other participant in the conversation is still engaged in the conversation, and turn-taking signals which may include fixed expressions such as 'you know', 'but' or may take the form of prosodic, paralinguistic or syntactic units.

By taking these premises into consideration, one cannot claim that conversation itself is the subject of conversation analysis. Schegloff $(Y \cdots \vee)$ states that the real subject of conversation analysis is talk-ininteraction and not conversation. Talk-in-interaction is a term coined by Schegloff himself and refers to 
“any activity of interactive talk, independent of its purpose” (ten Have, । १९९: $)$ ). Terminologically, talkin-interaction is preferred over conversation because CA research is not limited to what is usually considered conversation. Such a comprehensive interpretation of conversation allows researchers to use CA to study casual conversation as a form of social behavior, as well as more task- or institution-oriented conversation, such as calls to help lines, talk in classrooms or talk on mass media.

\section{r. Institutional Talk}

For the sake of limiting the scope of the study to its real purpose, it is important to identify what institutional talk is. For the most part, works in CA focus on ordinary conversation. This term has come to denote "forms of interaction which are not confined to specialized settings or to the execution of particular

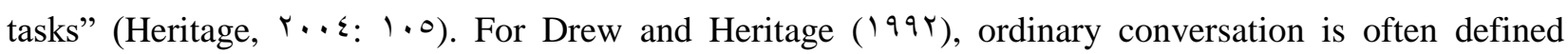
negatively, whereas wedding ceremonies are not ordinary conversation and so are legal proceedings in court and TV shows, though they practically adapt practices of talk and action from ordinary conversation and press them into service in these more specialized and restricted speech settings.

In contrast, the studies of institutional talk which began to emerge in the late $19 \mathrm{~V} \cdot \mathrm{s}$ focus on more restricted environments in which:

(i) The goals of the participants are more limited and institution-specific.

(ii) Restrictions on the nature of interactional contributions are often in force.

(iii) Institution- and activity-specific inferential frameworks are common.

(Drew and Heritage, 199r: $\leqslant \varepsilon$ )

Ordinary conversation includes many rules and practices, which are exploited to do every imaginable kind of social goal, and which encompass an indefinite array of inferential frameworks. Institutional interaction, by contrast, involves a reduction in the range of interactional practices deployed by the participants, restrictions in the contexts they can be deployed in, and it frequently involves some specialization and respecification of the interactional relevance of the practices that remain (ibid: $\leqslant 0$ ). However, such kind of talk-in-interaction can also give an indication about the nature of encounter signals and the way they are influenced by socio-cultural backgrounds despite the degree of reduction it shows as compared with ordinary talk.

\section{r. Entry and Exit strategies}

In a previous section, we have introduced Goffman's four universals of communication signals, including both opening and closing of conversation which are regarded as basic concepts in the way to conversational analysis that seeks interactional framework rather than a purely linguistic one. Most of the researches and theorizing about openings and closings of conversations have been done based on data from telephone conversations, where conversational analysts claimed that the findings from such data are applicable to many other types of conversation, if not all, as "for the most part the organizational problems

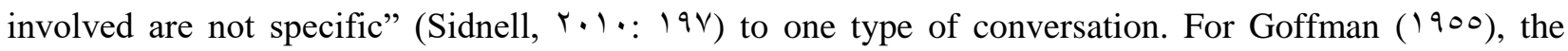
reasonable assumption, that every language has a range of forms to be used as greetings and farewells, is 
based on the social importance of entries and exits which are borrowed from the stage to reflect the fact that discussions of speech norms often compare them with the lines that the actor recites on the stage (cited in: Hudson, 1997:1 rr).

Goffman ( $197 \mathrm{~V}:\{1)$ states that Greetings provide a way of showing that a relationship is still what it was at the termination of the previous co-participation, and, typically, that this relationship involves sufficient suppression of hostility for the participants temporarily to drop their guards and talk. Farewells sum up the effect of the encounter upon the relationship and show what the participants may expect of one another when they next meet. The enthusiasm of greetings compensates for the weakening of the relationship caused by the absence just terminated, while the enthusiasm of farewells compensates the relationship for the harm that is about to be done to it by separation.

\section{r.1 Entry Strategies}

Turn-taking strategies are governed by certain set of rules which interpret how to locate turns regularly in conversations; yet, these rules do not determine who starts speaking first. Schegloff (19人૫) formulates rules about conversational openings based on openings of calls to a disaster center. Analyzing these calls with their exceptions has led him to the terms of summons-answers sequences. Such an analysis is not limited to telephone calls, summons are also used in face-to-face conversation. It can be noted at the outset that a summon - often called an "attention-getting device" (Schegloff, I $9 \wedge 7: r / 1$ ) is not a telephonespecific occurrence. Other classes besides mechanical devices, such as telephone rings, include:

1. $\quad$ Terms of address (e.g., "John?,"" Dr.," "Mr. Jones?,""waiter," etc.)

r. $\quad$ courtesy phrases (e.g., "Pardon me," when approaching a stranger to get his attention)

r. Physical devices (e.g., a tap on the shoulder, waves of a hand, raising of a hand by an audience member, etc.). (Schegloff 191\%: 1.^•)

The summons themselves also have the form of questions and they also have much of the same characteristics. By producing an answer (when a child yells Mom? ... Mom!, the mother may answer What is it?). Summonses are used to check the availability of possible participants for interaction. Even when they are present, they may be otherwise engaged.

Schegloff (19人7) writes that the opening section of conversation in telephone calls seems to require four sequences, which are:

1. A summons-answer sequence: addressing the interactional task of establishing the channel and the availability of the participants for the interaction;

r. An identification/recognition sequence: establishing the identity of the participants in the conversation.

r. A greeting sequence: ratifying participation;

؛. How are you? sequences: provide opportunities to make some state of being a matter for talk in the conversation or to pass this up as a relevant action at this point in the talk. 
Each of these sequences is usually achieved in either a two-turn adjacency pair or in three turns as an adjacency pair with a sequence closing third. These sequences form a sequence of sequences which are organized relative to each other. They can be organized serially so that each turn at talk deals with one part of the sequence and the sequence progresses turn by turn. These sequences are also abbreviated to three core sequences, namely, greeting, recognition, personal-state inquiry. The three core sequences lead to the "anchor position", a term coined by Schegloff (1917) to refer to the position following these core sequences when the first topic will be raised. This position can be considered as the end of the opening.

\section{r. Exit strategies}

According to Schegloff \& Sacks ( $९ \vee \mathrm{Y} \mathrm{Y}$ •) a conversation "does not simply end, but is brought to a close". Likewise, we depend on the sequence of conversation in order to understand what is going on. There would be social implications that ought to worry about if a closing sequence does not go as we had expected it to. You cannot simply walk away during a conversation to end it. Something must be done to make walking away or hanging up the phone a natural conclusion instead of something that can be understood as communicating anger or boredom.

A conversation consists of different turns: participants take turns at being the speaker and hearer, but "the distribution of turns-at-talk operates locally, organizing just current and next turn" (Sidnell,,$\cdot) \cdot$ : Y (O): it does not determine what will be the last turn. Each completion of a turn allows for a participant to

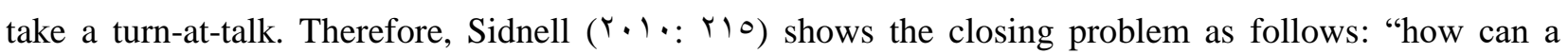
possible completion be so constructed that it will not be understood as an opportunity for another speaker to take a turn?". For Schegloff and Sacks ( $19 \vee r: ~ r 90)$, the solution to that problem is a "terminal exchange" which removes the transition relevance at the end of the second turn. A terminal exchange is an adjacency pair: the first pair part is a proposal to end the conversation, the preferred second pair part is an acceptance of that proposal (ibid). All of this can be achieved by a simple exchange of goodbyes, for instance. Naturally, a terminal exchange is only a part of the solution. It cannot follow just any previous turn. It would be very odd if you were to answer a question like "How is your work? by starting a terminal exchange. Your conversational partner might be face-threatened due to this response. Even if the questionanswer adjacency pair had been completed, a terminal exchange still has to be introduced: it is the final part of a larger structure within the conversation. A terminal exchange is properly used at the end of a closing section. Bringing a conversation to a close does not only involve the local operation of turn-taking, it involves larger structures and organization, "in particular, the organization of topic talk, and the overall

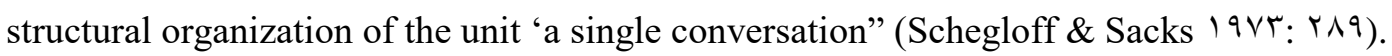

One can open up a closing by using a possible pre-closing (Schegloff \& Sacks 19vץ). Closing sequences can only be started once the main topic of conversation has been completed. In such a closing relevant environment, one of the participants in the conversation can then ask whether there is anything else relevant to discuss, by using a pre-closing token. In English, this is often done through the use of Okay? or Alright?, while in Arabic it is often done through (حسناً؟) (إذ؟ن) (so) oray) .

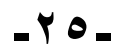


Rui and Ting $(Y \cdot 1 \varepsilon)$, working on conversation structure in TV shows, have found that a complete closing includes three main sequences; topic bounding sequence, pre-closing sequence and closing sequence.

\section{Methodology}

The data on which this paper bases his claims are two episodes of The Doctors show in its American and Arabic version. This show focuses on subjects of public health, including reports and direct interviews with medical specialists, patients and public figures. So that different kinds of conversations are provided. The paper analyzes only one interview of each episode focusing on the conversational structures and sociolinguistic consequences.

The data were analyzed to identify the degrees of similarities and differences in English and Arabic entry and exit strategies, pointing out their social meaning and the socio-cultural factors that shape them. This is an empirical study which is basically descriptive, but the inductive approach is indispensable for conversational analysis.

\section{Analysis of Entries and Exits in English}

\section{Entry strategies in English}

To follow the four strategies of opening a conversation highlighted above, the show starts with applause and cheers. This is in fact part of the show protocol, yet, it can be regarded as Schegloff's summons-answer sequence which establishes the channel and the availability of the participants for the interaction and motivate the doctor/broadcaster to start speaking as an answer to the summon sequence which is in this case can be regarded as a sort of physical device made by the audience.

The doctor/broadcaster greets the audience verbally and non-verbally by raising hand. This nonverbal use is also regarded as a sign through which the broadcaster/doctor is trying to take the turn and starts the conversation. This is what he actually does by saying;

- Welcome, welcome,

Then, he goes directly to the 'anchor position' raising the first topic of the show by saying:

We are starting the show with one of the brightest and busiest stars in Hollywood....

The broadcaster then turns to initiate a new entrance and necessarily a new conversation, introducing the visiting guest, usually with the help of a video, which informs the audience of background information of the guest. This step is mainly addressed to the audience so as to help them understand and appreciate the program better by providing the contextual framework of conversation.

Please welcome the four times Grammy nominated, best selling author and the big movie star: Tyreeeese. (The guest shows up along with music)

At this stage, we can say that two of entrance strategies are mixed up. The summons-answer sequence and the identification/recognition sequence. This is due to the broadcaster/doctor using only one sentence to serve two functions, first; to introduce the potential participant in the conversation, and second, 
to establish the channel and the availability of the participant for the interaction. This is mainly made through mentioning the guest's name with rising intonation. The guest in turn does not answer the summon verbally but nonverbally, through jut entering the show.

In such kind of face-to-face interaction, we see that the identification/recognition sequence precedes the summon-answer sequence although they are tackled by only one utterance, but the final part of the utterance which is "Tyreeeese" functions both as part of the identification sequence and an address term which is practically part of summon-answer sequence. What enhances this idea is that the 'guest' answers the summon by showing up and entering the stage.

Once the guest shows up, there is a very short greeting sequence in which the two participants use adjacency pairs:

- Host: Hello

- Guest: Hello friend, how you doin'?

Again, two strategies or sequences are mixed but this time by the guest himself, who uses both a greeting sequence and 'how are you' sequence together. On the host part, the 'how are you' sequence is exceeded as the host does not reply, yet, this does not threaten the guest's face because of the high solidarity reflected through the entrance and the conversation. For the most part, this is the case in most conversations concerning institutional talk and TV shows in specific.

The guest, then, starts talking using a sort of phatic communion before the formal conversation:

Guest: I love it, I love it,

Turning to the audience with a physical device using eye-gaze and hand-raise, saying:

- Guest: I love you too.

For Rui and Ting $(Y \mid \Sigma)$, phatic communion provides no important information but sets up a communicative bridge and creates a harmonious atmosphere to make good preparation for the following formal interaction. The phatic communion here takes the form of a compliment utterance. The guest shows his compliment and high solidarity for both the guest and the audience by repeating the words "I love it, I love it, I love you too". After this, the formal conversation begins with anchor position by raising the first topic

- Host: I know that you are doing acting more singing lately, but can we get that LADIES when you sing?

\section{7. $\quad$ Exits strategies in English}

The paper has already presented Rui and Ting $\left(Y_{+}\right) \leqslant$) findings while working on conversation structure in TV shows, which states that a complete closing includes three main sequences; topic bounding sequence, which is also called termination point, pre-closing sequence and closing sequence. However, the exit section is an influential factor of conversation. A successful closing should be naturally transited from 
body in order to make guest prepare for the termination and lead audience to endless aftertaste. The closing part in The Doctors Show is flexible, but it follows the three-step sequence.

The termination point, as the first strategy to exit, is identified in the show by getting back to the first topic in the conversation which is "Paul Walker's death" the dearest friend of the guest 'Tyrese'. The host makes the topic bounding sequence through a terminating signal which in this case is indicated by "so". He says;

Host: So, we know that you went through a tragedy, loosing one of your best friends Paul Walker .... We want to send out condolences to you and to his family.

The guest agrees the termination point and prepare for the exit through answering and then ending with "so" too. The pre-closing sequence here is not mutually made, but, it is done by the guest who as we have just mention prepare for the exit.

Going on to talk about condolences, he says:

- Guest: And to his friends and to whole cast and everybody... Nicest guy in the world, that's why we still sad and try to recover of what I mean.... Aaah look at my friend, my guy .... We love you Paul and thank you for making the difference in our world, so!

The host then takes the turn and makes another pre-closing sequence on his part, by urging the audience to donate for Paul Walker charity organization, offering every one of them Tyrese's last DVD.

The closing sequence is now fully established and since we have noted that the conversation is flexible, the closing strategy is not restricted to 'good-byes', instead, it takes the following form:

- Host: Tyrese, thank you so very much for coming here today

- Guest: Oh, god bless you

What is notable here, besides avoiding good-byes, are two more things. Firstly, as in the entry, the host uses an address term within the exit strategy. The term of address includes the name only "Tyrese" without a title of respect or profession. This is for Hudson (1997) reflecting a high solidarity between the speaker and the hearer. Concerning power, one can say, that the hearer in this case has socially less power because of the fact that he is a guest in TV show, but this does not lead to say that the guest is a close subordinate. Instead, he can be best regarded as a close equal. This intermediate situation, according to Hudson (1997), varies from person to person and that we are all guided by our experience of other people's behaviour so we expect to find regularities not only in each person's behaviour but also across individuals. Hudson further comments that we are all rather uncertain about the choice of names when dealing with cases other than the clear ones.

The second thing is that the use of religious sentiment in the exit strategy, where the guest ends up with “Oh, god bless you”. In general, religious sentiments are not frequently used in modern entrance and exit strategies in English (Rui and Ting: $r_{+} \mid \varepsilon$ ). This is due to socio- cultural and socio-religious reasons 
with the influence of globalization and many other factors. However, exit strategies may sometimes include religious sentiments especially in the closing sequence and that what the paper has just noted.

\section{v. Entry and Exit Strategies in Arabic}

We need to note first that the data of this paper seem to be identical and even a photocopy in some cases. Since the Arabic version of The Doctors Show is just an exact imitation to the American version. Once you watch the Arabic show, you notice that the correspondence is even intended to appear in the use of language itself. Meanwhile, the language, with all the attempts, shows a good deal of difference and this is due to the difference in the socio-cultural backgrounds of the two versions, the Arabic and the English one.

What we seek here is not the use of language in particular, but more importantly, the paper tries to look for two more factors, which are; the potential universality of entrance and exit strategies, especially between two different languages and communities and degree to which the two types of conversation are sociolinguistically different. This is what the paper is going to observe by analyzing one of the episodes of the Arabic version of The Doctors show.

\section{v.l Entry strategies in Arabic}

Like the American version, the show starts with applause and cheers. It can also be regarded as summon for the doctors to start conversation by answering the sequence. The broadcaster/doctor starts greeting the audience verbally and non-verbally by raising hand. This non-verbal use is also regarded as a sign through which the broadcaster-doctor is trying to take the turn and starts the conversation. This is what he actually does by saying;

مرحبا أعز ائي المشاهدين ، نرحب بكم في برنامجكم The Doctors

- $\quad$ Hello dear viewers, welcome you in The Doctors show

Then, he goes directly to the 'anchor position' raising the first topic of the show by saying:

$$
\text { اليوم بنتكلم عن أسرار اللون الأبيض، أأ حنه طبعاً ما نتكلم عن أندية وفانيلة بيضة ، لا ، بنتكلم عن مواد ومأكو لات لونها أبيض .... }
$$

Today, we are going to talk about the secrets of the white colour, of course we are not talking about sport clubs and white shirts, but about white foods and white items.

The broadcaster/doctor prepares to take the role of the host, trying to initiate a new entrance and a new conversation. As a host, he starts introducing the visiting guest, informing the audience of background information about him. This step is mainly addressed to the audience so as to help them understand and appreciate the program better by providing the contextual framework of conversation.

$$
\text { خلنه نستعين في حد خبير فهالموضوع، معانا في الأستوديو الدكتورة وفاء عايش }
$$

- Let's make use of on of the experts in this topic, the doctor Wafaa Ayesh is joining us in the studio

$$
\text { ( تدخل الدكتورة الى المسرح مع تصفيق الجمهور ) }
$$


As with the American show, the identification/recognition strategy is preceding the summon/ answer strategy, yet, the two are mixed up where naming the guest serves as a summon that is answered by the guest entering the stage.

Once the guest shows up, the greeting sequence takes action and the participants start to use relatively prolonged series of adjacency pairs:

$$
\text { - }
$$

Unlike the American show, where two sequences are mixed, we have here a separate and relatively prolonged greeting sequence in which the guest uses • "hellos" and I "happy new year". Of course, the greeting strategy takes the adjacency-pairs form with the host answering the greeting. Then, the "how are you' sequence is indicated directly by the guest, saying "كيفك" (how are you) and yet there is no answer from the host to complete the adjacency pair, we can see that the guest face is not threatened since the host managed to use a sort of compliment by saying "أحنه لازم نستعين بالخبراء" (we need to consult experts).

After greeting, the host uses the identification sequence again, and what should be noted here is the kind of address term he uses where he says:

$$
\text { المضيف : دكتورة وفاء اختصاصية التغدية ، طبعا احنه لازم نستعين في الخبراء }
$$

Using the title of profession as an address term, this reflects the fact that the guest is a distant superior. For Hudson ( $1997: 1 \mathrm{r}$ r), this kind of address terms is used if there is low solidarity and the guest has more power than the speaker. In fact, we know that the two participants are doctors with relatively the same social class, yet the guest is presented as distant superior. The reason behind this lies in two important things. First; Arabs seem to be more aware of the socio-cultural background, and second the age is always taken into consideration. In this interview, the guest is an old lady while the host is a young doctor.

Phatic communion takes place then, before starting the formal conversation, where the host and the guest exchange a religious adjacency pair, saying to each other;

$$
\text { - }
$$

After that, the formal conversation begins with anchor position where the host raises the first topic;

$$
\text { - - المضيف : مثل ما شفنا السكر موجود في كل شي ، حتى لو قلنا ..... هذا غذاء طبيعي ولا مفيد .... }
$$

\section{v.r Exit Strategies in Arabic}

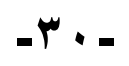


The TV shows are always flexible. The exit strategies within them do not always follow the three established sequences of ending a conversation. This is due to the fact that a TV show is a kind of institutional talk in which the topic of conversation takes the major attention rather than the entries and exits and that is why they are described as more flexible than in normal conversations.

In the Arabic version of The Doctors show, the termination point where topic is bounded seems to be not quite clear. The host only asks the guest:

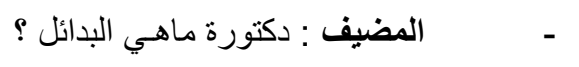

Taking her turn in the conversation, to speak about the alternatives of "too much using sugar", both the host and the guest do not express any strategy of topic bounding. However this is compensated by mixing both the pre-closing sequence and the closing sequence, again, by both the host and the guest. They say:

$$
\text { - }
$$

Like the American version, The closing sequence, due to the flexibility of TV shows and institutional talk in general, is not restricted to 'good-byes', instead, it takes a thanking and welcoming form.

Again and as in the entry section, religious sentiment is used. In general, religious sentiments are frequently used in entry and exit strategies in Arabic. This is due to socio-religious reasons. In come use, most or even all the Arabic entry and exit strategies are made of religious sentiments. (Rababah and Malkawi: $r \cdot 11)$

\section{$\wedge$. Discussion}

It seems to be that there is a kind of agreement on the universality of entry and exit strategies across linguistically, although they are varying considerably in some superficial details. This is, as we are going to discuss, a matter of cultural, social, religious and even regional diversity. The discussion of entry and exit strategies in English and Arabic will focus on sociolinguistic and discoursal factors, taking into consideration matters of politeness, power and solidarity, age and sex in addition to the entries and exits structure between the two languages.

\section{A.) Politeness}

Watts ( $r \cdots r: 9)$ states that politeness is not something we are born with, but a set of skills that we have to learn and acquire. People ordinarily follow certain socio-cultural norms of linguistic etiquette in order to show politeness and courtesy to each other. An indirect but immense contribution to the politeness research was made by Erving Goffman with his notions of 'face' and 'ritual order'. Goffman (1900: r Tr) defines face as "the positive social value a person effectively claims for himself by the line others assume he has taken during a particular contact", in other words it is the conceptualization each of us makes of our 'self' through the construals of others in social interaction and mainly through talk (Watts, r..r:I r ). 
Face is not a permanent entity; it is only 'on loan from society' (ibid: I ro). It implies that we are like 'players in a ritual game' (ibid: I rr). So, if we want our faces to be saved, we need not to threaten other's face. This can be taken for granted as a general rule that one should follow.

Concerning this paper, high but flexible degrees of politeness and face-saving acts are identified. For sure, the topic under analysis is a TV show and such situations politeness should be taken into consideration. Generally, the Arabic show reveals a higher degree of politeness. This is due to socioreligious backgrounds where Arabs are highly influenced by the Islamic conventions. We can deduce this claim from the ample use of religious sentiments during the entries and exits of the conversation.

\section{^. Y Power and Solidarity}

Speech reflects the social relations between the speaker and the addressee, most particularly, the power and solidarity manifested in that relationship. For Holmes $\left(r \cdot 1 r_{:}\right) r r$ ) power reflects the difference in social status and the hierarchical order that the community takes, while Hudson ( $\left.1997: 1 r^{r}\right)$ defines solidarity as "the social distance between, how much social characteristics they share, and how far they are prepared to share intimacies". Practically, we indicate and analyze power-solidarity relations through certain linguistic markers which reflect the social relations between the participants of a conversation.

The Arabic and American version in this study show different order of power-solidarity relations. This might be taken into consideration as a sketch about the nature of tackling these relations in the two different communities. Thus, higher solidarity is revealed in the American show with equity in power relations, despite the fact that the guest of the show is a well-known Hollywood star. In Arabic, careful treatment must be paid to power and solidarity. We can see that the guest is treated as a distant superior along the show. In turn, the guest also treated the hosts as distant superiors too, although all the participants engaged in the conversation are of the same profession and necessarily the same social class. All these indications are built on the use of the word "doctor" as an address term. For Hudson ( $1997: 1$ r० $^{\circ}$ ), wherever power and solidarity are reflected in the same range of forms, the form which expresses high solidarity also expresses greater power and vice versa.

\section{^.r Age and Sex}

Age and sex are important factors which causes linguistic variation in social interactions. Sociolinguistically, they have received a good deal of interest because of the way they are indicated linguistically. As in politeness and power-solidarity relations, and due to socio-cultural and socio-religious perspectives, the Arabic version of the Doctors Show reveals a careful management of age and sex. The study has previously stated that age and sex may affect the power-solidarity relations whereas the participant use address terms in order to take into account the age and sex of the addressee and this will lead to affect the nature of the power-solidarity relations. On the other side, the American version of the show pays less attention to these two factors and this also based on socio-cultural perspectives. The show reflects a high degree of solidarity and that is why the two factors. Especially age, seems to be a little bit marginal.

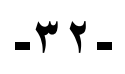




\section{^.\& Entries and Exits Structures}

In the first chapter, the study has noted that entries and exits constitute what is called the overall generalization, which is in turn only one part of the conversation structure besides turn-taking and adjacency pairs. The study also adopts Schegloff, Sacks, and many others' sociologists and linguists who divided entries and exit into sequences, four major sequences for entering a conversation and mainly three for exiting it. However, it is important to note that these sequences may overlap or even vary from person to person and place to another according to socio-cultural variations.

By comparing the use of strategies between English and Arabic, the variation seems to be quite clear although the analysis tackles the same show in two different languages with relatively the same settings and the protocols.

What we need to note first is that sequences are frequently overlapping regardless of language and socio-cultural differences. The analysis has shown that summon-answer sequence and identification/recognition sequence overlap in the American show, while in Arabic; the overlap appears in the pre-closing and the closing sequences.

Second, Arabic conversation, pays more attention to the 'how are you sequence', so that the entries and exits are almost longest than the English conversation with frequent use of phatic communion. At this point, the socio-cultural variation is quite clear between the two languages, where Arabs regard the relative long 'how are you' sequence as part of the politeness and etiquette.

Third, Arabic conversation focus little on the topic-bounding sequence. This necessarily does not include all the exit strategies, but only the termination point in which the participants prepare to end the conversation. The analysis has shown that Arabic conversation tends to shift directly to the pre-closing sequence without bounding the topic first. The same thing does not happen in the English conversation which appears to have a clearly established termination point in which the topic is fully bounded.

Lastly, the structure of Arabic entry and exit strategies include a big deal of religious sentiments. As we have noted before, this is due to socio-cultural and socio-religious backgrounds of Arabs. Both Arabic language and Islam provides more religious greetings and farewells than English this is at least in recent time.

\section{Conclusions}

Language is commonly used through conversation. So that, it is needed to study conversation in face-to-face interaction in order to understand the mechanisms according to which a language operates. Sociolinguists affirm that conversation analysis is not concerned directly with conversation as its subject but with talk-interaction. This is, in turn, has different types of structures and two of them are entries and exits. For entries and exits, they are built on certain strategies which seem to be universal at some points, although the great deal of flexibility they always show. 
It is a commonsense that one cannot enter or exit a conversation at random. One should prepare and skillfully manage the strategies of entry and exit because they enfold social considerations and others' face in a direct way. The use of entrance and exit strategies also gives indications of different social relations such as power, solidarity, age, sex, culture, etc. All these amounts of information are reflected in greetings and farewells, so, they should receive a good deal of interest.

Entry and exit strategies vary from person to person and from place to another. Crosslinguistically, they also show considerable variation, although the strategies themselves seem to be fixed enough to be built upon. For Arabic and English, entries and exits appear to follow the same set of strategies, yet, they show certain differences in the way the strategies are used. This is because of the huge difference on many scales including linguistic, social, cultural, religious and regional backgrounds.

\section{References}

Brown, G., Yule G. (। १^५). Discourse Analysis. Cambridge: Cambridge University Press.

Brown, P., Levinson, S. C. ( $19 \wedge \vee$ ). Politeness: Some universals in language use. Cambridge: Cambridge University Press.

Coulthard, M. (19^०) An Introduction to Discourse Analysis. London: Longman.

De Boeck, J. $\left(Y^{*} \mathbf{l O}^{\circ}\right)$ Opening and Closing Strategies in YouTube Vlogs: How Monologues Encourage Conversation, M.A. Thesis.

Franke, K. E. (Y.। ) Between Institutional Talk and Everyday Conversation: The Language Use of Television, Doctoral Dissertation

Goffman, E. (1900) On Face-Work: An Analysis of Ritual Elements in Social Interaction. Harmondsworth: Penguin Books.

Goffman, E. ( $197 \mathrm{~V})$. Interaction ritual: essays on face to face behavior. New York: Anchor Books.

Goffman, E. ( $(9 \vee \varepsilon)$ Frame Analysis: An Essay on the Organization of Experience, Boston: Northeastern University Press

Gumperz, J. J. ( $(9 \vee \backslash)$ ). Language in Social Groups. Stanford: Stanford University Press.

Gumperz, J.J. ( (१^r) Discourse Strategies, Cambridge: Cambridge University Press.

Gumperz, J.J. $\left(Y_{\cdots}\right.$ ) $)$. Interactional Sociolinguistics: A Personal Perspective. In Schiffrin, D., Tannen, D., Hamilton, H.E. eds.

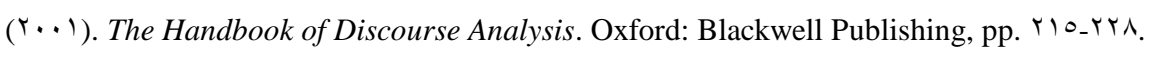

Heritage, J. ( $\ldots \varepsilon)$, Conversation analysis and institutional talk, in R. Sanders and K. Fitch (eds), Handbook of Language and Social Interaction. Mahwah NJ: Lawrence Erlbaum (pp. $\left.1 \cdot r_{-} \varepsilon \tau\right)$.

Holmes, J. ( ( १९ ). An Introduction to Sociolinguistics. London: Longman.

Hudson, R. A. ( $९ \vee \wedge)$. Sociolinguistics. Cambridge: Cambridge University Press.

Lerner, G. H. (ץ. . ¿ $)$ Conversation Analysis: Studies from the first generation, Amsterdam: John Benjamins Publishing Company.

Levinson, S. C. ( $(9 \wedge$ ). Pragmatics. Cambridge: Cambridge University Press.

Liddicoat J. Anthony ( $(. . \vee$ ) An Introduction to Conversation Analysis, London: Continuum

Rababa`h. A. Mahmoud and Malkawi A. Nibal ( $(+11)$ The Linguistic Etiquette of Greeting and Leave-Taking in Jordanian Arabic, European Scientific Journal,vol. ^, No. \^, P । $\varepsilon_{-} \uparrow \wedge$

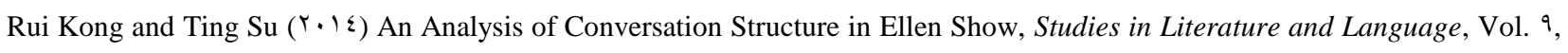
No. r, p. rv-乏Y

Sacks, H., Jefferson, G and Schegloff, E (1990) Lectures on Conversation: Volumes I and II, Blackwell Publishing.

Sacks, H., Schegloff E. A., Jefferson G. ( $9 \vee \varepsilon)$ A Simplest Systematics For The Organization of Turn-Taking In Conversation. Language $0 \cdot(\varepsilon)$, pp. тят_vт०.

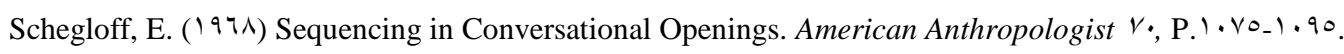

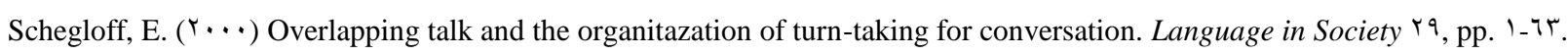

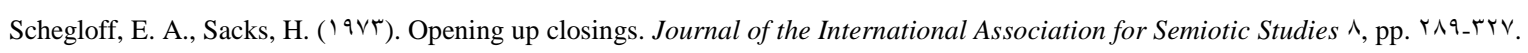

Ten Have, P. ( 1999$)$ Doing Conversation Analysis: A Practical Guide. London: Sage.

Wardhaugh, Ronald, $19 \wedge 0$. How Conversation Works. Oxford: Basil Blackwell.

Watts, R.J., (ץ..r). Politeness. Cambridge: Cambridge University Press. 